\title{
USE OF CUSTOM MADE PEEK PLATES FOR TREATMENT OF MANDIBULAR FRACTURE
}

\author{
Noha Y. Dessoky* BDS, Ahmed S. El-Mahallawy² PhD, Magued H. Fahmy² PhD, \\ Mervat M. Khalil ${ }^{2} \mathrm{PhD}$
}

\begin{abstract}
INTRODUCTION: Maxillofacial injuries, such as soft-tissue injuries, dental injuries, or maxillary, mandibular, and zygomatic fractures; are the most common injuries treated by oral and maxillofacial surgeons. In the last few years polyetheretherketone (PEEK) material was recognized as a material for maxillo-facial and cranial reconstructions.

OBJECTIVES: The aim of this study is to evaluate the use of custom made polyetheretherketone (PEEK) plate in the treatment of mandibular fracture.

MATERIALS AND METHODS: 10 patients having non-comminuted recent mandibular fracture will be treated using custom made PEEK plates. Clinical follow up will be conducted after 24-hours, one week, 1 month, 3 months and 6 months. Also, a radiographic investigation will be performed after 6 months to estimate the mean bone density across the fracture line.

RESULTS: Data will be collected, summarized and statistically analyzed using the suitable methods.

CONCLUSIONS: Fixation of mandibular fracture with custom made PEEK plate provides satisfying clinical and radiographic results after 6 months follow up.

KEYWORDS: Mandibular fracture, PEEK.

RUNNING TITLE: Use of PEEK in mandibular fracture.

1 Assistant Lecturer Department of Oral and Maxillofacial Surgery, Faculty of Dentistry, Alexandria University Egypt.

2 Professor, Department of Oral and Maxillofacial Surgery, Faculty of Dentistry, Alexandria University, Egypt.

*Corresponding author

E-mail:dr_nohayoussry@hotmail.com
\end{abstract}

\section{INTRODUCTION}

Maxillofacial trauma is a common presentation following injury to the face (1). The management of craniomaxillofacial (CMF) traumatic injuries can be difficult (2).

Mandible fracture is the most typical fracture as a result of being the foremost outstanding bone within the face and is commonly broken over the supported middle third of the face accounting for $20 \%-60 \%$ of all facial fractures (3). These injuries cannot solely be serious (as they will compromise airway or can cause vital hemorrhage) however conjointly cause

disfigurement. So, the most intent of mandible fractures management ought to be the patient come to the pre-existing state of activity and aesthetics $(4,5)$.

Mandibular fracture can be simple, closed, compound, or comminuted. It can also be greenstick fracture, comminuted fracture, complex fracture, depressed fracture, impacted fracture and pathological fractures. It can also be classified according to the presence or absence of the teeth in the jaws (Dentulous, Partially edentulous, Edentulous) (6).

Fractures of the lower jawbone are ideally treated with open reduction and internal fixation by an intraoral or extraoral approach. Direct bone contact between the fracture segments supports primary bone healing, that results in earlier bone regrowth and stability across the fracture site $(7,8)$.

Computers are getting used more and more as an accessory tool for diagnosis and surgical procedure designing in craniomaxillofacial (CMF) field $(9,10)$. They are employed in conjunction with digital imaging techniques like computerized tomography (CT) and cone beam computed tomography (CBCT) to enhance image of anatomical and physiological conditions $(10,11)$.

Many materials can be used in the process of fabrication of internal fixation devices, one of the recent materials is Polyether-ether-Ketone (PEEK).

Poly-ether-ether-Ketone is a semi-crystalline polyaromatic linear polymer that exhibits a superb combination of stiffness, strength, environmental resistance and biocompatibility (12). It is turning into progressively helpful, and provides rather more predictable and stable results, because it resembles cortical bone biomechanically (13).

Today, PEEK materials, are largely applied in different surgical and medical fields. The PEEK based implants are an alternative of titanium based and ceramic implants in a cranial, maxillo-facial, orthopedic and spine surgeries (14).

Therefore, the aim of this study is to evaluate the use of custom-made PEEK plate in the treatment of mandibular body fracture.

\section{MATERIALS AND METHODS}

The study was performed after gaining the ethical clearance from the Research Ethics Committee, Faculty of dentistry, Alexandria University.

An informed consent was signed from all patients after explaining all the procedures to the patient including al benefits and side effects in a simple and easy way.

Ten patients were selected from the Emergency Ward of Alexandria University Teaching Hospital and were operated 
upon in the Oral and Maxillofacial Surgery Department, Faculty of Dentistry, Alexandria University.

Patients were selected based upon:

- Adult Patients above 18 years old with no gender predilections.

- Patients suffering from recent, uninfected, non-comminuted mandibular body fracture.

- Unfavourable fracture that demands open reduction and internal fixation.

High resolution CT of the mandible was performed (with slice thickness $1 \mathrm{~mm}$ ). computer-guided reduction was done using specialized software (MIMICS; Materialise NV, Belgium) with surface-based rendering for surgical planning. CT images in a DICOM (Digital Imaging and Communications in Medicine) format were exported into the segmentation software (MIMICS). A segmentation process was carried out in the following steps:

- 2D section images were used to define the image thresholds so as to eliminate all of the soft tissue and only highlighting bone and dental tissues.

- Mandibular bone and teeth were further selected and a three dimensional reconstruction of the segmented mandible along with dental hard tissue was created.

- The reconstructed mandible was further segmented into individual fracture segments. (Figure 1)

- The fracture segments were then virtually repositioned and reduced anatomically using the simulation module (repositioning option) of the above software. (Figure 2)

- Virtual reduction of mandibular fracture was verified in the axial and coronal planes and condylar position was checked in relation to the glenoid fossa

- Two custom plates are then planned on the simulated reduced mandible. (Figure 3 )

- The image is then transferred to a machine (MC X5; Dentsply Sirona Susquehanna, USA) so that the plate can be milled from a PEEK disk (bredent, breCAM.BioHPP, Germany.

All of the patients underwent open reduction and internal fixation of mandibular fractures under general anesthesia administered through naso-endotracheal intubation. The surgical field was scrubbed with povidone-iodine (7.5\% (0.75\% available iodine), Purdue Products L.P) surgical scrub solution, followed by draping of the patient with sterile towels exposing only the area of surgery. Fracture line/s were exposed through either intra-oral, extra-oral or trans-buccal approach. Mobilization of the fracture, removal of any soft tissue entrapped within fracture line and management of teeth in the fracture line either by extraction or preservation. Followed by bone reduction into proper anatomical occlusion. Inter maxillary fixation (IMF) was temporarily secured to provide proper occlusion that served as a guide for fracture reduction. Placement of the custom-made PEEK plates in place and fixed by mini screws (Figure 4). The MMF was removed and the surgical field was irrigated with Povidone-iodine and saline in preparation for wound closure.

\section{Statistical analysis of the data}

Data were fed to the computer and analyzed using IBM SPSS software package version 20.0. (Armonk, NY: IBM Corp) Qualitative data were described using number and percent. The Kolmogorov-Smirnov test was used to verify the normality of distribution Quantitative data were described using range (minimum and maximum), mean, standard deviation and median. Significance of the obtained results was judged at the $5 \%$ level.

\section{The used tests were}

\section{1 - ANOVA with repeated measures}

For normally distributed quantitative variables, to compare between more than two periods or stages, and Post Hoc test (Bonferroni adjusted) for pairwise comparisons

\section{2 - Friedman test}

For abnormally distributed quantitative variables, to compare between more than two periods or stages and Post Hoc Test

(Dunn's) for pairwise comparisons

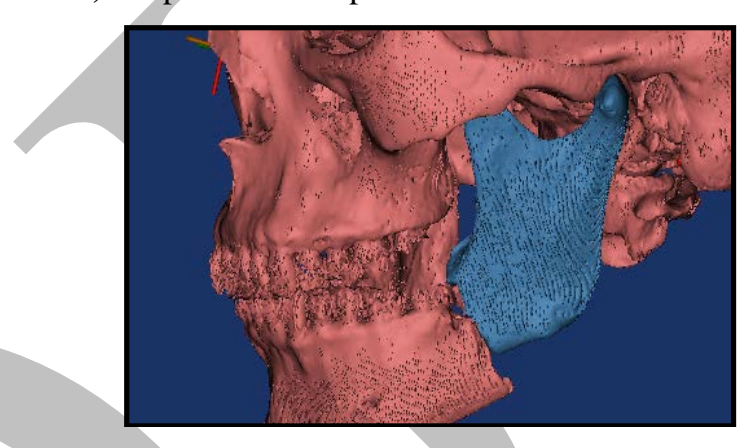

Figure (1): 3D reconstructed mandible before reduction.

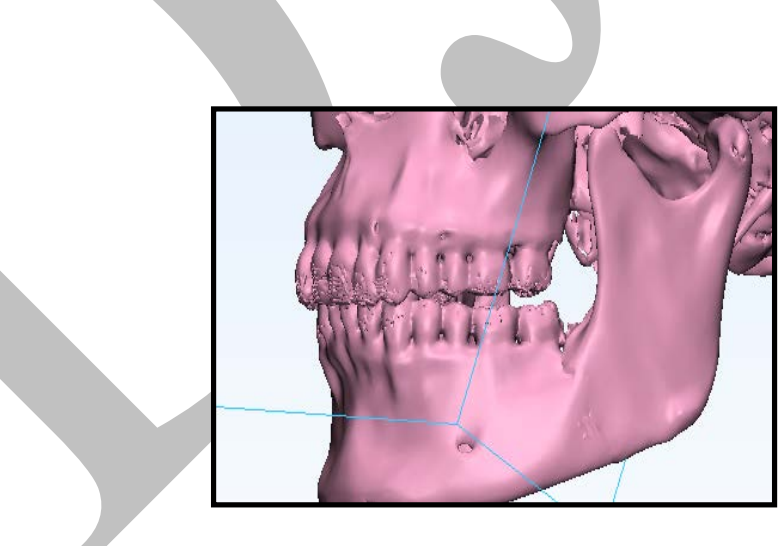

Figure (2): The segments after virtual reduction.

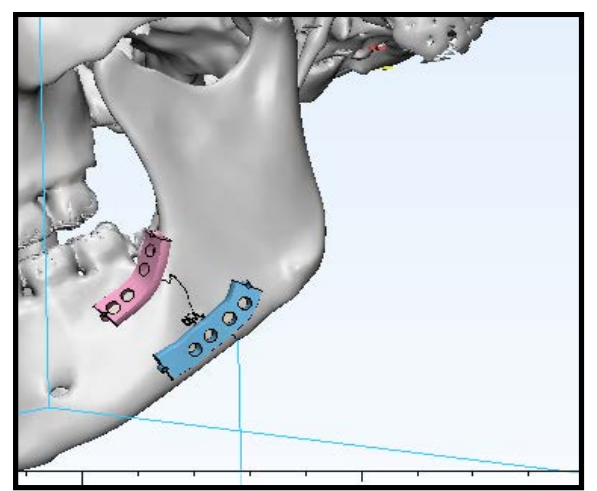

Figure (3): PEEK custom plates after being planned on the virtually reduced mandible. 


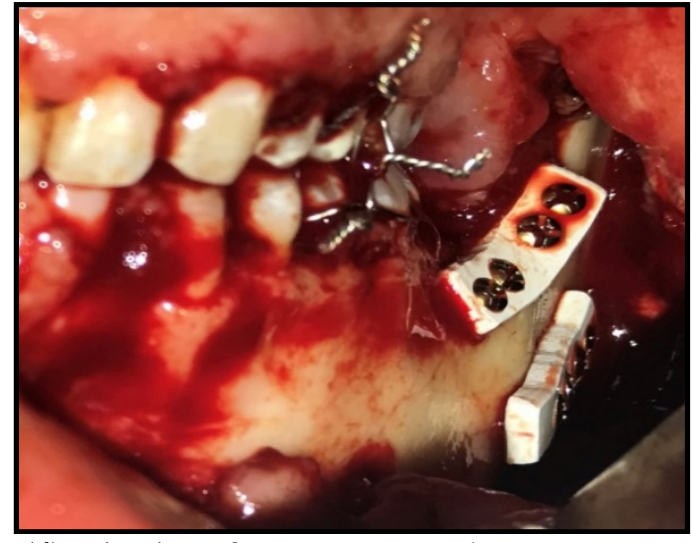

Figure (4): Fixation of PEEK custom plates.

\section{RESULTS}

Sample was composed of 10 patients (10 men). Occlusion was achievable in all the patients. The mean age of the patients was $30.67 \pm 9.31$. The surgical procedure went uneventful in all of the patients. Postoperative edema and pain (Table 1) were reported by all of the patients, which, however, resolved before the first recall visit at 1 week postoperatively. Postoperative CT views showed satisfactory reduction of the fractures. Each subject had one preoperative CT-Scan and three postoperative CT-Scans, one was taken immediately postoperatively, one at three months and one at six months.

The mean bone density at the fracture site was calculated by measuring bone density at 6 points in the vicinity of the fracture line using CBCT software then taking their averages to determine the immediate postoperative, 3 months' postoperative, and 6 months' postoperative mean bone density. All of the measurements were in Hounsfield Units (HU). (Table 2)

Table (1): Descriptive analysis of the studied cases according to pain VAS

$(\mathrm{n}=10)$.

\begin{tabular}{|l|l|c|c|c|c|c|c|}
\hline Pain & \multicolumn{1}{|c|}{$\begin{array}{c}\mathbf{2 4} \\
\text { hours }\end{array}$} & $\begin{array}{c}\mathbf{1} \\
\text { week }\end{array}$ & $\begin{array}{c}\mathbf{1} \\
\text { month }\end{array}$ & $\begin{array}{c}\mathbf{3} \\
\text { months }\end{array}$ & $\begin{array}{c}\mathbf{6} \\
\text { months }\end{array}$ & Fr & \multicolumn{1}{|c|}{ p } \\
\hline $\begin{array}{l}\text { Min. }- \\
\text { Max. }\end{array}$ & $3.0-5.0$ & $0.0-3.0$ & $0.0-2.0$ & $0.0-0.0$ & $0.0-0.0$ & & \\
$\begin{array}{l}\text { Mean } \\
\pm \text { SD. } \\
\text { Median }\end{array}$ & $3.92 \pm 0.79$ & $1.92 \pm 1.24$ & $0.67 \pm 0.65$ & $0.0 \pm 0.0$ & $0.0 \pm 0.0$ & $42.523^{*}$ & $<0.0$ \\
\hline p1 & 2.0 & 1.0 & 0.0 & 0.0 & & \\
\hline
\end{tabular}

Fr: Friedman test, Pairwise comparison bet. each 2 groups were done using Post Hoc Test (Dunn's)

$\mathrm{p}$ : $\mathrm{p}$ values for comparing between the five studied periods

$\mathrm{p}_{1}$ : $\mathrm{p}$ values for comparing between 24 hours and other periods

*: Statistically significant at $\mathrm{p} \leq 0.05$
Table (2): Descriptive analysis of the studied cases according to bone density $(\mathrm{n}=10)$ in Hounsfield Unit (HU).

\begin{tabular}{|l|l|l|l|l|l||}
\hline $\begin{array}{l}\text { Bone } \\
\text { density }\end{array}$ & Immediate & $\mathbf{3}$ months & $\mathbf{6}$ months & $\mathbf{F}$ & $\mathbf{p}$ \\
\hline $\begin{array}{l}\text { Min. }- \\
\text { Max. }\end{array}$ & $600.0-750.0$ & $630.0-1100.0$ & $900.0-1200.0$ & & \\
$\begin{array}{l}\text { Mean } \pm \\
\text { SD. } \\
\text { Median }\end{array}$ & $706.7 \pm 44.38$ & $900.4 \pm 148.55$ & $1057.5 \pm 108.3$ & $60.175^{*}$ & $<0.001^{*}$ \\
\hline $\begin{array}{l}\text { Sig bet. } \\
\text { periods }\end{array}$ & $\mathrm{p}_{1}=0.002^{*}, \mathrm{p}_{2}<0.001^{*}, \mathrm{p}_{3}<0.001^{*}$ & 1100.0 & \\
\hline
\end{tabular}

F: $\mathrm{F}$ test (ANOVA) with repeated measures, Sig. bet. periods were done using Post Hoc Test (Bonferroni)

$\mathrm{p}$ : $\mathrm{p}$ values for comparing between the three studied periods

$\mathrm{p}_{1}$ : $\mathrm{p}$ values for comparing between immediate and 3 months

$\mathrm{p}_{2}$ : $\mathrm{p}$ values for comparing between immediate and 6 months

pз: $p$ values for comparing between 3 months and 6 months

*: Statistically significant at $\mathrm{p} \leq 0.05$

\section{DISCUSSION}

Mandibular fractures are considered one of the most common fractures encountered by the CMF surgeons. Although several techniques have been reported for the treatment of these types of fractures including different designs of prosthetic devices, accurate anatomical bone reduction cannot be guaranteed. Therefore, ORIF is the method of choice to obtain perfect anatomical reduction, especially in fractures with severely displaced bone segments $(7,8)$.

Thanks to its bone-like elasticity (elastic modulus: three four GPa), the material PEEK (polyetheretherketone) may be a viable different material. It's been beneficially applied as an implant material in various medical fields since the 1990s (14) thanks to its high stability, low density $(1.32 \mathrm{~g} / \mathrm{cm} 3)$ and insolubility (15).

To our knowledge, this is the first study to report prospective clinical and radiographic outcomes after fixation of a mandibular body fracture with custom-made PEEK plates.

Poly-ether-ether-Ketone plates have been used in the treatment of ankle fractures in a study that compared the use of conventional stainless steel plates and PEEK plates by Matteo Guzzini et al (16). The results showed high similarity of the two fixation devices at 6, 12 and 24 months of clinical and radiographic follow-up, which was in an agreement with a previous study published in 2014 by Caforio et al (17).

Schliemann et al., in 2015 reported a comparison of PEEK and conventional plates for the treatment of 3- or 4- part proximal humerus fracture which showed PEEK plate did not provide equal fixation strength when compared to a conventional titanium locking plate (18).

Experimental studies that compared PEEK and titanium rods in spine surgeries and concluded that the higher flexibility of PEEK decreases stresses at the bone-screw interface. Others that compared titanium and PEEK plates of similar shapes lead to the hypothesis that the lower rigidity of PEEK fixation may decrease the risk of screw pullout/pushout (18).

PEEK plates were already studied for other orthopedic procedures, but there are few studies from trauma surgery (16). 


\section{CONCLUSION}

Fixation of mandibular fracture with custom made PEEK plate provides satisfying clinical and radiographic results after 6 months of follow-up.

\section{REFERENCES}

1. Kaura S, Kaur P, Bahl R, Bansal S, Sangha P. Retrospective Study of Facial Fractures. Ann Maxillofac Surg. 2018; 8:78-82.

2. Bui TG, Bell RB, Dierks EJ. Technological advances in the treatment of facial trauma. Atlas Oral Maxillofac Surg Clin North Am. 2012; 20:81-94.

3. Gassner R, Tuli T, Hächl O, Rudisch A, Ulmer H. Cranio-maxillofacial trauma: a 10 year review of 9543 cases with 21067 injuries. J Craniomaxillofac Surg. 2003; 31:51-61.

4. Hull AM, Lowe T, Finlay PM. The psychological impact of maxillofacial trauma: an overview of reactions to trauma. Oral Surg Oral Med Oral Pathol Oral Radiol Endod. 2003; 95:515-20.

5. Klotch DW. Frontal sinus fractures: anterior skull base. Facial Plast Surg. 2000; 16:127-34.

6. Passi D. Newer Proposed Classification of Mandibular Fractures: A Critical Review with Recent Updates. Ann Med Health Sci Res. 2017; 7:314-8.

7. Perren SM, Huggler A, Russenberger M, Straumann F, Muller ME, Allgower M. A method of measuring the change in compression applied to living cortical bone. Acta Orthop Scand Suppl. 1969; 125:7-16.

8. Batbayar EO, van Minnen B, Bos RRM. Non-IMF mandibular fracture reduction techniques: A review of the literature. J Craniomaxillofac Surg. 2017; 45:1327-32.

9. Talwar RM, Chemaly D. Information and computer technology in oral and maxillofacial surgery. Oral Maxillofac Surg Clin North Am. 2008; 20:79-89.

10. el-Gengehi M, Seif SA. Evaluation of the accuracy of computer-guided mandibular fracture reduction. J Craniofac Surg. 2015; 26:1587-91.
11. Edwards SP. Computer-assisted craniomaxillofacial surgery. Oral Maxillofac Surg Clin North Am. 2010; 22:117-34.

12. Kim MM, Boahene KDO, Byrne PJ. Use of Customized Polyetheretherketone (PEEK) Implants in the Reconstruction of Complex Maxillofacial Defects. Arch Facial Plast Surg. 2009; 11:53-7.

13. Patel N, Kim B, Zaid W. Use of Virtual Surgical Planning for Simultaneous Maxillofacial Osteotomies and Custom Polyetheretherketone Implant in Secondary Orbito-Frontal Reconstruction: Importance of Restoring Orbital Volume. J Craniofac Surg. 2017; 28:387-90.

14. Kurtz SM, Devine JN. PEEK biomaterials in trauma, orthopedic, and spinal implants. Biomaterials. 2007; 28:4845-69.

15. Schwitalla AD, Zimmermann T, Spintig T, Kallage I, Muller WD. Fatigue limits of different PEEK materials for dental implants. J Mech Behav Biomed Mater. 2017; 69:163-8.

16. Guzzini M, Lanzetti RM, Lupariello D, Morelli F, Princi G, Perugia D, et al. Comparison between carbon-peek plate and conventional stainless-steel plate in ankle fractures. A prospective study of two years follow up. Injury. 2017; 48:1249-52.

17. Caforio M, Perugia D, Colombo M, Calori GM, Maniscalco P. Preliminary experience with Piccolo Composite $^{\mathrm{TM}}$, a radiolucent distal fibula plate, in ankle fractures. Injury. 2014;45: S36-S8.

18. Schliemann B, Seifert R, Theisen C, Gehweiler D, Wahnert D, Schulze $M$, et al. PEEK versus titanium locking plates for proximal humerus fracture fixation: a comparative biomechanical study in two- and three-part fractures. Arch Orthop Trauma Surg. 2017; 137:63-71. 